\title{
A Phenomenological Experience of Trainer with COVID-19 Training: A Tertiary Level Institution Experience with Simulation
}

Kusum K Rohilla ( $\square$ kus2211@gmail.com )

All India Institute of Medical Sciences

\section{Arun Varghese}

Advanced Centre of Medical Education, AllMS,

C Vasantha Kalyani

All India Institute of Medical Sciences

Neha Singh

All India Institute of Medical Sciences

\section{Shalinee Rao}

Advanced Centre of Medical Education, AllMS,

\section{Research Article}

Keywords: COVID-19, phenomenological, trainer, training program

Posted Date: August 11th, 2021

DOl: https://doi.org/10.21203/rs.3.rs-794702/v1

License: (9) This work is licensed under a Creative Commons Attribution 4.0 International License. Read Full License 


\section{Abstract}

Background: Highly infectious diseases like COVID-19, which are rapidly disseminating and exceedingly contagious, require vital safety skills to be followed by all health professionals. These safety skills need to be taught to all individuals working in the health care sector, by qualified trainers. The present study describes the experiences of COVID-19 trainers who were involved in providing this intensive training to health workers, in a tertiary level institution. The hospital was providing services to COVID positive patients, as well as emergency and tertiary care services during the COVID-19 pandemic. Most of the participants in the study were high risk groups who were in direct interaction with COVID positive patients.

Methods: The COVID-19 training program was conducted for more than three months, with the aim of training all the health care workers at a tertiary care institute, during the Corona virus pandemic. Twenty trainers, who had completed at least 30 or more sessions of training more than 2700 health workers, were included in this study. These trainers were interviewed for an average of thirty minutes per participant and were asked 30 open ended questions each.

Results: The mean age of the trainers was 28.9 years, and $75 \%$ of them were females. The interview of the COVID-19 trainers highlighted four important factors, which according to them were the pillars of this successful and effective training program. These factors included: The use of video demonstration and simulation for the training; Regular updating of the skill of the trainers in this program; Ease of communication to address the challenges faced by the trainers; and strong administrative support for the training.

Conclusion: The results of this study reveal that if health workers are provided a conducive environment for training, as well as full support for updating their knowledge and skills, they can provide optimal health care services to their patients and fellow healthcare workers, even during a challenging time like the COVID-19 pandemic. The trainers in this study provided training to all the health care workers of the hospital, who were posted in COVID wards, even at a time when everyone had the fear of contracting the infection.

\section{Background}

The beginning of the year 2020 marked the spread of the deadly COVID-19 pandemic, which sent the health care system of the world into a frenzy. ${ }^{(1)}$ At that point, the world did not know how to deal with this highly communicable disease. There were not enough information available for health professionals to deal with this communicable virus. ${ }^{(2)}$ This pandemic totally disrupted and shook the global health care delivery system. The World Health Organization (WHO) ${ }^{(3)}$ and Ministry of Health and Family Welfare $(\mathrm{MoHFW})^{(4)}$ started providing online information, and shared literature for health care professionals to update their practices on how to deal with this infection and hoe to work in COVID areas. This was a new infection and the lacunae of knowledge pertaining to its clinical course, led to a feeling of fear and uncertainty amongst health care workers across all cadres. Despite the availability of information from 
WHO and MOHFW, the health care professionals were apprehensive about the fear of contracting this disease while providing health care services to COVID positive patients. Even the healthcare systems were doubtful whether the provided protocols were being followed efficiently, and whether these would effectively protect the frontline workers from the deadly COVID-19 virus, while discharging their duties.

Our institute is a tertiary care centre, which was functioning as a COVID hospital during the pandemic. The institute was providing services to COVID positive patients, along with routine emergency and tertiary care services to sick patients. Hence, there was a pressing need to train all the health care workers, with the aim of allaying their fears of contracting this highly contagious infection, by following standardized protocols. Hence the institution started a COVID-19 training program for all health workers including doctors, nurses, paramedical staff and other supporting staff. The training program involved diverse educational methods for teaching, since it is well documented that multiple teaching methodologies lead to more responsive teaching as compared to a single method. This study describes the experiences of twenty trainers/ instructors who undertook the mammoth task of providing the COVID-19 training to over 2700 health care workers, during the COVID-19 pandemic when the fear of them contracting the infection themselves was looming over.

\section{Methods}

\section{Study design, procedure and sample}

The present study was a qualitative study with a phenomenological research design which was conducted by The Advanced Centre of Continuous Professional Development, AllMS, Rishikesh. The study was conducted on 20 COVID-19 trainers/ instructors who were involved in training more than 2700 health care workers, during the challenging COVID-19 pandemic. The study aimed to describe the experiences of these trainers, as well as the challenges and difficulties faced by them in executing this huge and daunting task.

This training program was a huge program which was well organized by The Advanced Centre of Continuous Professional Development, AlIMS, Rishikesh as per the protocol laid down by WHO and Government of India. The training program was conducted from April to July 2020 , and during this duration, more than 2700 health professionals were trained. More than 65 sessions were conducted for doctors, 110 sessions for nurses, 80 sessions for paramedical staff and 75 sessions for other supporting staff of the hospital.

Before starting this rigorous training program, the trainers had to be identified and trained. Instructor training mainly includes general and specific training. ${ }^{(5)} \mathrm{A}$ total of 30 trainers were voluntarily selected from various departments. They were then provided specific training for two days, by the CPD, AlIMS Rishikesh. The training module content for the trainers was prepared as per guidelines of WHO and MoHFW. The two days training session was followed by a post-test examination, which required a 
minimum of $75 \%$ marks for qualifying as a trainer. The trainers who successfully completed the training and qualified the exit examination were involved in the training program.

During these training sessions, the recommended trainer: students ratio of 1:10(6) which was maintained throughout. Each participant was trained for two days. The sessions were planned meticulously and combined two methods of teaching. The first part of the training was by didactic lectures and the rest of it was simulation-based training. The COVID-19 training content module was divided into sections: general training and specific training. General training was provided to each health worker regarding general precautions like do's and don'ts for prevention of infection while working in hospital, donning and doffing of personal protective equipment (PPE) and standard safety precautions to be taken by all health care workers. The specific training topics were tailored according to the specific work profile of the health workers. For example, doctors and nurses were trained to collect throat swabs from patients and performing laryngoscopy on COVID-19 positive patients. Paramedical staff were specifically trained about the precautions to be taken while handling COVID-19 samples, disinfection and sterilization of instruments and equipment's used for COVID-19 positive patients. Other supporting hospital staff were trained regarding disinfection and general sanitation of wards, handling of biomedical waste, and special precautions to be taken while handling the dead body of a COVID-19 positive patient. [Table 1] The twoday training was followed by a post-test examination with minimum qualifying marks of $50 \%$.

Table 1

General and Specific Training Topics for Health Workers

\section{General Training Topics}

1. General precautions to be taken while working in hospital

2. Hand hygiene

3. Do's and don'ts while working in hospital

4. Donning and doffing PPE

5. Activities to be performed before entering to home

\section{Specific Training Topics}

\section{Doctors and Nurses:}

- How to take throat swabs

- Laryngoscopy of COVID-19 positive patient

- Biomedical waste management

Paramedical staff:

- How to handle COVID-19 samples

- Disinfection and sterilization of instruments and equipment used for COVID-19 areas

- Biomedical waste management

Other supportive staff:

- Sanitation

- Biomedical waste management

- Special precaution while handling dead body of COVID19 positive patients 
Twenty COVID-19 trainers who took more than 30 sessions in the training program were included in the study. Data collection was done by interviewing each trainer about his/her experience of the COVID-19 training program. The interview was based on a questionnaire with thirty questions which were semistructured and open ended. The questions pertained to teaching/learning methods used in the training program, assessment methods, method to obtain feedback from participants, facilitating factors, and the challenges faced by the trainers in planning and executing this training module.

\section{Statistical Analysis Plan}

Each trainer was interviewed for an average of 30 minutes, and all the interviews were recorded.

Transcription of each recorded interview was accurately done word by word. Qualitative data interpretation was done after each interview. Collected data was reexamined in depth by primary codes also. After gathering data, the main points were noted down and a theme and subtheme were drawn out of this information. Data analysis was done using MAXQDA software. ${ }^{(7)}$

Ethical approval for this study was taken from the Institutional Ethical Committee. Written informed consent was obtained from each participant of the study. Anonymity and confidentiality of each participant was maintained during the whole study.

\section{Results}

\section{Sample characteristics}

Twenty trainers were included in the study, and $75 \%$ of them were females. The mean age of the trainers was 28.9 years. The group equally consisted of demonstrators and faculty, most of whom had 5 to 10 years of teaching experience. Each trainer conducted 30-40 sessions. The majority of participants who underwent training were other hospital staff including pharmacists, housekeeping staff, dietitian and supporting staff. Remaining $25 \%$ were nursing staff and faculty of hospital. [Table 2] 
Table 2

Bio-demographic variables of trainer $(n=20)$

\begin{tabular}{|c|c|c|c|c|}
\hline $\begin{array}{l}\text { Sr. } \\
\text { No. }\end{array}$ & Variables & Options & Frequency & Percentage \\
\hline 1. & Age & Mean \pm SD & $28.9 \pm 3.4$ & \\
\hline \multirow[t]{2}{*}{2.} & \multirow[t]{2}{*}{ Gender } & Male & 15 & 75 \\
\hline & & Female & 05 & 25 \\
\hline \multirow[t]{2}{*}{3.} & \multirow[t]{2}{*}{ Designation } & Demonstrator/Tutor & 10 & 50 \\
\hline & & Faculty & 10 & 50 \\
\hline \multirow[t]{3}{*}{4.} & \multirow[t]{3}{*}{ Years of teaching experience } & Less than 5 years & 03 & 15 \\
\hline & & $5-10$ years & 12 & 60 \\
\hline & & More than 10 years & 05 & 25 \\
\hline \multirow[t]{3}{*}{5.} & \multirow{3}{*}{$\begin{array}{l}\text { Conducted number of sessions in } \\
\text { COVID-19 training }\end{array}$} & $30-40$ & 10 & 50 \\
\hline & & $40-50$ & 05 & 25 \\
\hline & & More than 50 & 05 & 25 \\
\hline \multirow[t]{3}{*}{6.} & \multirow[t]{3}{*}{ Participants of their course } & $\begin{array}{l}\text { Faculty (Doctor + } \\
\text { Nurses) }\end{array}$ & 05 & 25 \\
\hline & & Nursing staff & 05 & 25 \\
\hline & & Other hospital staff & 10 & 50 \\
\hline
\end{tabular}

After analyzing the data collected after interviewing the trainers about an effective training program, the following points emerged. According to the trainers, an effective training program consisted of:

\section{Use Of Appropriate Teaching Learning Methods}

COVID-19 trainer showed overwhelming response during the whole training session. Eight trainers said that the video demonstration was followed by a discussion of queries, which was the main teaching learning method used in health system training in undergraduate and postgraduate learning. According to the trainers, this was the best part of this training. A few trainers were in support of lecture cum discussion methods used in training sessions.

Since the training was conducted during the COVID pandemic, majority of the trainers found this method as the most appropriate method, since it ensured social distancing during the training sessions, thereby preventing spread of infection to the trainers. The trainers also agreed that the fastest mode of training during any pandemic, is to create and prepare a big taskforce of trainers. 
The trainers felt that the best method to assess competency during this training was use of simulation, which provided the learner a real-life experience in a controlled environment. Simulation was an integral part of the various training sessions conducted during the pandemic. According to most trainers, the best method to obtain feedback from participants was post-test after completion of training, which also fulfilled the criteria for summative evaluation.

\section{Updating Skills Of Health Workers Routinely}

All trainers feel satisfied that they are provided training to all health workers of the hospital during the pandemic. On an average, each trainer clarified about 6 to 10 doubts of participants in each session. This indicated that health workers did have a lot of doubts and incorrect concepts about the pandemic, which needed clarification. The trainers felt that this type of a training program should be conducted at the institutional level during any pandemic situation, to empower our health taskforce for any crisis. The trainers felt that the whole concept of the COVID-19 training was the need of the hour during the pandemic ad felt that it was a well-planned and meticulously executed program. They also felt that every health worker should regularly update their skills for any communicable disease. The trainers also felt that participating in this program helped them brush their skills and acquire essential knowledge about the COVID-19 pandemic.

\section{Administrative Support And Other Motivating Factors}

The most important motivating factors which facilitated the trainers during this training program, was full support from the hospital administration. The needs of the trainers and the equipment required for the program were given priority by the administration, and this facilitated the whole program. The administration also ensured that the hospital workers were provided appropriate safety equipment and PPEs to prevent them from getting infected while working with COVID-19 positive patients.

Another factor which motivated the trainers was the meticulously planned sessions. Eight trainers said that the program was well planned, and they all were aware and well informed about their training schedules well in advance. Most of the participants were highly motivated and showed full interest during the training sessions, which also served as one of the driving forces for the trainers.

Most of the COVID-19 trainers were self-motivated. They all felt that it was their moral duty to provide training to health workers to combat this deadly virus, at the time when the country and world were facing the deadly pandemic. This was another major factor which kept the trainers motivated at a time when the fear of infection was looming high. Some of the trainers were felt that strong and frequent positive reinforcement from administration and organizers of this program motivated them to work efficiently. Table 3 summarizes the various factors that contributed to an effective training program. 
Table 3

Response and Subtheme of COVID-19 trainer experience $(\mathrm{n}=20)$

\begin{tabular}{|c|c|c|}
\hline \multirow[t]{2}{*}{ Theme } & \multirow[t]{2}{*}{ Subtheme } & Trainer verbatim \\
\hline & & 'Response' \\
\hline \multirow{13}{*}{$\begin{array}{l}\text { Teaching } \\
\text { learning } \\
\text { method }\end{array}$} & \multirow[t]{5}{*}{$\begin{array}{l}\text { Best teaching method for this } \\
\text { module }\end{array}$} & $\begin{array}{l}\text { Video instruction i.e., video demonstration } \\
\text { and discussion of queries (08) }\end{array}$ \\
\hline & & Lecture cum discussion (07) \\
\hline & & Demonstration (02) \\
\hline & & Simulation (02) \\
\hline & & Online (01) \\
\hline & \multirow[t]{3}{*}{ Reasons to select this method } & $\begin{array}{l}\text { To prevent spread of COVID-19 infection, } \\
\text { safety of HCW, maintain social distancing, } \\
\text { increase task force (12) }\end{array}$ \\
\hline & & $\begin{array}{l}\text { For better understanding, and for enhancing } \\
\text { the skills of participants (05) }\end{array}$ \\
\hline & & Feasible (03) \\
\hline & \multirow{3}{*}{$\begin{array}{l}\text { Best method for assessment of } \\
\text { competency which was used in } \\
\text { this module }\end{array}$} & Simulation (08) \\
\hline & & $\begin{array}{l}\text { Re-demonstration and questioning in between } \\
\text { the session (06) }\end{array}$ \\
\hline & & Post-test after completion of training (06) \\
\hline & \multirow{2}{*}{$\begin{array}{l}\text { Best method to obtain feedback } \\
\text { from participants which was used } \\
\text { in this module }\end{array}$} & Post-test after completion of training (12) \\
\hline & & Google form (08) \\
\hline \multirow{4}{*}{$\begin{array}{l}\text { Update skill of } \\
\text { health } \\
\text { workers } \\
\text { routinely }\end{array}$} & \multirow{2}{*}{$\begin{array}{l}\text { How many doubts / } \\
\text { clarifications/ questions were } \\
\text { asked by participants to you per } \\
\text { session }\end{array}$} & Less than 5 doubt per session (01) \\
\hline & & $6-10$ doubt per session (19) \\
\hline & \multirow[t]{2}{*}{ Other experiences } & $\begin{array}{l}\text { It was a well-planned module and was very } \\
\text { essential for us to update our skills (18) }\end{array}$ \\
\hline & & $\begin{array}{l}\text { Well planned and full contribution from } \\
\text { administration (02) }\end{array}$ \\
\hline \multirow[t]{3}{*}{$\begin{array}{l}\text { Administrative } \\
\text { support }\end{array}$} & \multirow{3}{*}{$\begin{array}{l}\text { Factors that facilitated you during } \\
\text { training of participants in this } \\
\text { module }\end{array}$} & $\begin{array}{l}\text { Well planned sessions, Interest from } \\
\text { participants }(08)\end{array}$ \\
\hline & & $\begin{array}{l}\text { High fidelity mannequin, advanced supporting } \\
\text { softwares, adequate space at the venue to } \\
\text { maintain social distance (08) }\end{array}$ \\
\hline & & Teaching Module (02) \\
\hline
\end{tabular}




\section{Theme}

Subtheme

Trainer verbatim

'Response'

Interest and participation of participants (02)

Factors that facilitated you in scheduling of this module

Support from administration and organisers, Motivation to educate HCWs (18)

Video based teaching was helpful in every session (02)
Factors that facilitated you in planning of this module

Urgent need of country and institute and to prepare adequately trained workforce to combat the COVID-19 pandemic (15)

Positive reinforcement from administration (05)

Your expectations met as a COVID-19 trainer
Yes, Feel satisfied (20)

Figure 1 showing overall schematic framework of COVID-19 training provided to all hospital health professionals at a tertiary care level institution during COVID-19 pandemic.

\section{Discussion}

Novel coronavirus i.e. COVID-19 was identified as the main cause of a respiratory illness outbreak, which originated from Wuhan, China in late December 2019, which then spread to the whole world as a global pandemic. WHO had started various online training programs to help health care professionals and front line workers to assess, recognize and manage this environmental related diseases? However, this being a new disease which was highly contagious, led to fear and apprehension amongst the health care professionals worldwide. To address this pressing issue, our Institute took the initiative to start a formal training program to educate all health care professionals working at the Institute, about COVID19, and to make them aware of the do's and don'ts during the COVID19 pandemic.

In this study, we tested a different type of prototype for effective training of all health care professionals. We demonstrated the training experience of twenty trainers who don't have any prior experience of task force preparedness. Novice trainers who were trained belongs to diverse groups. For training, they used simulation-based courses followed by hands-on simulation training for all health care professionals. Both trainers and trainees showed a wide spectrum of educational backgrounds indicating towards the effectiveness of this course for all levels of health care workers.

In this study, we elaborately explored the experience of trainer regarding their training experience. By notifying their experience, researcher try to explore twenty newly trained COVID-19 trainers experience in COVID-19 preparedness without prior experience. Newly trained trainer, successfully trained in simulation courses, a diverse range of health care workers including doctors, nurses, paramedical staff and other 
supportive staff. Another study conducted on trainer experience during Ebola virus showed simulation method is effective techniques for trained health professionals. ${ }^{(8)}$

COVID-19 trainer and health professionals all belong to versatile spectrum with different educational backgrounds, which indicates that the course is comprehensively plan to cover every aspect of preparedness during any pandemic scenario in future as well. Another study also recommended that health workers should be effectively and properly communicated to combat any pandemic. ${ }^{(9)}$

No formal training for all health care workers was available in India; as this COVID-19 pandemic escalated in 2019 a urgent need for health care workers capacity and confidence building was felt. To address, this issue health care workers program was initiated at tertiary care level institutions using their available resources of for pandemic outbreak and strengthen health care workers capacity. Through this training program, knowledge, skills and confidence among healthcare workers was boosted. After completing this training, there was a significant reduction in infection rate among health care workers which indicated the success of this training as well as trainer. A study was conducted in Liberia to train all HCWs during EBOLA outbreaks which all focuses of importance of training for HCWs. ${ }^{(10)}$

The training program was conducted by COVID-19 trainer at a tertiary level institution, and it was a big program which was well organized with the full support of the administration. [Figure 2] Trainer identify that administration support is necessary for a program to achieve huge success. Another study also showed that for any training schedule for all health care workers, need full administrative support to make it a success. ${ }^{(11)}$

In this study, one important point which were highlighted that the best teaching and learning method in COVID pandemic era were video demonstration followed by discussion of queries. Another study finding suggested that in COVID-19 pandemic, online teaching and learning process break hurdles and create a linkage between learning and technology. ${ }^{(12)}$

The third most important aspect, which came in limelight from the study, was always updating the skills of health workers on a regular basis, which is the responsibility of every institution to whom they are serving. The study also suggested that health workers' knowledge must be improved and updated and it should be considered as top priorities of any health care facilities. ${ }^{(13)}$ Always emphasize on regular training of health professional for updating their skills. Every institution must address the challenges faced by its employees for the best outcome.

\section{Challenges Faced By The Trainers}

The trainers faced few challenges during training of health care workers. The challenge that was unanimously faced by all the trainers was the fear of contracting the infection while taking sessions for groups of participants. Despite social distancing being followed and dividing the participants into small groups to avoid crowding, this fear was present throughout. The other challenge faced was exhaustion 
from conducting many sessions per day, since the number of HCWs was high and training had to be provided during a limited period of time. [Table 4]

Table 4

Challenges faced by COVID-19 trainer $(n=20)$

\begin{tabular}{|c|c|c|}
\hline \multirow{5}{*}{$\begin{array}{l}\text { Challenges } \\
\text { faced by the } \\
\text { trainers }\end{array}$} & \multirow[t]{3}{*}{$\begin{array}{l}\text { Challenges in training of participants in } \\
\text { this module }\end{array}$} & $\begin{array}{l}\text { Fear of infection spread to themselves } \\
\text { (10) }\end{array}$ \\
\hline & & More than 5 sessions per day (05) \\
\hline & & Social distancing (05) \\
\hline & \multirow[t]{2}{*}{$\begin{array}{l}\text { Challenges you faced in planning of this } \\
\text { module with reference to COVID- } 19 \\
\text { pandemic }\end{array}$} & $\begin{array}{l}\text { Fear of infection spread, paucity of time, } \\
\text { large number of taskforces to be trained } \\
\text { (16) }\end{array}$ \\
\hline & & Limited time \& social distancing (04) \\
\hline
\end{tabular}

\section{Conclusion}

In this project, we have seen teacher experiences who worker in pandemic scenarios. We have seen their experiences of training conducted during COVID-19 pandemic that could be a core part of any training in routine or emergency situation. All this experience provide a framework to tertiary level institution to think further for betterment of their health workers.

\section{Declarations}

\section{Availability Of Data And Materials}

Datasets used and analyzed for present study are available with corresponding author.

\section{References}

1. Singh AST, Machathoibi Chanu. COVID-19 pandemic wave: A global struggle and ways to control. Archives of Community Medicine and Public Health. 2020;6(2):179-85.

2. Liu Q, Luo D, Haase JE, Guo Q, Wang XQ, Liu S, et al. The experiences of health-care providers during the COVID-19 crisis in China: a qualitative study. The Lancet Global Health. 2020;8(6):e790-e8.

3. Ventola CL. Social media and health care professionals: benefits, risks, and best practices. Pharmacy \& Therapeutics: a peer-reviewed journal for formulary management. 2014;39(7):491-520.

4. Rao S, Rohilla KK, Kathrotia R, Naithani M, Varghese A, Bahadur A, et al. Rapid Workforce Development to Combat the COVID-19 Pandemic: Experience From a Tertiary Health Care Centre in North India. 2021;13(6).

5. Rodriguez-Valls F, Montes AA. A Teacher Training Experience Based on Work with Communities in California \%J Educación y Educadores. 2011;14:105-18. 
6. Snider KT, Seffinger MA, Ferrill HP, Gish EE. Trainer-to-Student Ratios for Teaching Psychomotor Skills in Health Care Fields, as Applied to Osteopathic Manipulative Medicine. Journal of the American Osteopathic Association. 2012;112(4):182-7.

7. Download MAXQDA demo version for Windows | MAXQDA 2019 [Available from: https://www.maxqda.com/download-maxqda-demo-version-for-windows.

8. Tobin CD, Alfred M, Wilson DA, MenkinSmith L, Lehman-Huskamp KL, Schaefer JJ, et al. Train-thetrainer: Pilot trial for ebola virus disease simulation training. Education for health (Abingdon, England). 2020;33(2):37-45.

9. de Rooij D, Belfroid E, Eilers R, Roßkamp D, Swaan C, Timen A. Qualitative Research: Institutional Preparedness During Threats of Infectious Disease Outbreaks. Biomed Res Int. 2020;2020:5861894.

10. Bemah P, Baller A, Cooper C, Massaquoi M, Skrip L, Rude JM, et al. Strengthening healthcare workforce capacity during and post Ebola outbreaks in Liberia: an innovative and effective approach to epidemic preparedness and response. The Pan African medical journal. 2019;33(Suppl 2):9.

11. Melton DI, Katula JA, Mustian KM. The Current State of Personal Training: an Industry Perspective of Personal Trainers in a Small Southeast Community. Journal of strength and conditioning research / National Strength \& Conditioning Association. 2008;22(3):883.

12. Mishra L, Gupta T, Shree A. Online teaching-learning in higher education during lockdown period of COVID-19 pandemic. International Journal of Educational Research Open. 2020;1:100012.

13. Slipicevic O, Masic I. Management Knowledge and Skills Required in the Health Care System of the Federation Bosnia and Herzegovina. Materia Socio-Medica. 2012;24(2):106.

\section{Figures}




\section{COVID-19}

Trainers

Inclusion criteria:

1. Trained as a health worker

2. Completed two days of COVID19 trainer training and qualified the exit examination

3. Conducted more than $\mathbf{3 0}$ training sessions

10 COVID-19 Trainers did not

fulfil the inclusion criteria

\begin{tabular}{|c|}
\cline { 2 - 2 } \multicolumn{1}{|c|}{} \\
\hline Best method \\
training for a huge \\
taskforce is video \\
based instruction \\
module followed by \\
discussion of \\
queries \\
\hline
\end{tabular}

\section{Figure 1}

Schematic framework of COVID-19 training 